\title{
"A gente fica muito tempo aqui dentro!": Reflexões sobre o trabalho de gerentes, recepcionistas e camareiras de hotéis ${ }^{1}$
}

\author{
Valquiria Padilha e Márcia Mazzeo Grande \\ Departamento de Administração da Faculdade de Economia, \\ Administração e Contabilidade de Ribeirão Preto da Universidade de São Paulo
}

\begin{abstract}
Partindo da premissa da centralidade do trabalho na vida das pessoas, o objetivo deste artigo foi compreender as relações entre os sentidos atribuídos ao trabalho e as condições concretas vividas por trabalhadores. Para isso, foram conduzidas 11 entrevistas em profundidade com gerentes, recepcionistas e camareiras de dois hotéis na cidade de Ribeirão Preto (SP), visando apreender a ótica dos próprios trabalhadores. As análises dos depoimentos possibilitam concluir que: a) os objetivos de vida dos entrevistados estão diretamente vinculados aos sentidos que eles atribuem ao trabalho; b) o trabalho é extenso e intenso, comprometendo o equilíbrio entre trabalho e vida pessoal; e c) os salários não condizem nem com as exigências de disponibilidade e de dedicação à empresa, nem com os objetivos de vida almejados.
\end{abstract}

Palavras-chave: Sentidos do trabalho, Centralidade do trabalho, Intensidade de trabalho, Hotelaria.

"We stay in here too long!": Reflecting on the work of hotel managers, receptionists and maids

Assuming the centrality of work in peoples' lives, this article aims to understand the living conditions of workers, from their point of view, through eleven in-depth interviews done with hotel managers, receptionists and maids of two hotels in the city of Ribeirão Preto, in the state of São Paulo. The analysis of the interviews leads to the following results: a) life objectives of the interviewed are directly connected to the feelings they have towards their work; b) the work is extensive and intensive, jeopardizing life-work balance; c) wages neither match the availability and dedication demanded by the company nor with aspired life objectives.

Keywords: Meaning of work, Centrality of work, Work intensity, Hotel industry.

Só quando entendermos que as empresas trabalham como comunidades para chegar à grandeza, e que as sociedades combinam necessidades sociais e econômicas para atingir o equilíbrio, é que começaremos a sair do abismo em que caímos (Mintzberg, 2007, p. 23).

\section{Introdução}

o instigante filme do cineasta Costa Gavras intitulado O Corte (França, 2005), o
personagem central da trama é Davert, um executivo demitido em busca de emprego que
decide eliminar seus concorrentes assassinando um a um. Um dos momentos mais fortes do
filme é quando ele está numa sessão com o terapeuta, que pergunta: "Todos os desempregados
sentem raiva e mágoa?". O terapeuta aconselha Davert a "ter uma visão positiva do problema",
afirmando "você não é o seu trabalho". Davert grita: "Roubando meu trabalho me tiraram a
vida! Sem trabalho eu sou o quêe?". O protagonista toca no cerne da questão: a centralidade do
trabalho na vida das pessoas e a sua importância mais que meramente financeira.

1 Agradecemos aos alunos Alexei José Zaratini, Jeferson Bráz de Lima e Renata C. Ancheschi Bonifácio, bolsistas PIBIC-CNPq que colaboraram na realização desta pesquisa. 
A temática da centralidade do trabalho na vida das pessoas não é nova nem se reserva a uma única área de investigação. A discussão dos sentidos e significados do trabalho entrelaça várias disciplinas e abordagens. Da sociologia à psicologia social, passando pela psicodinâmica do trabalho, diversos autores vêm analisando esse fenômeno que, num contexto de capitalismo globalizado apoiado em políticas neoliberais, é visto ora como uma bênção, ora como um castigo. Trabalhar é atividade fundante do ser humano e, por isso, sem trabalho não há vida, ou trabalhar é uma fonte de eterna escravidão à qual homens e mulheres estão condenados em todo o mundo?

Compreendemos o trabalho como atividade que conserva valor importante na sociedade e exerce uma influência considerável sobre as pessoas (Hackman \& Oldhan, 1975; Morin, 2001). Vários estudos, entre eles os de Morin (2001) e Mow (1987), apontaram que a maioria das pessoas continuaria trabalhando, mesmo se tivesse dinheiro suficiente para o resto da vida. Isto porque, segundo Morin (2001), além de fonte de sustento, o trabalho é oportunidade de relação com outras pessoas, oferece sentimento de vinculação, significa ter algo para fazer, pode evitar o tédio e trazer um objetivo para a vida.

Hoje, é possível falar do trabalho como uma categoria psicossociológica paradoxal e essencialmente contraditória, uma vez que, ao mesmo tempo, a atividade laborativa pode trazer saúde e doença aos trabalhadores, deixando-os felizes e tristes, satisfeitos e insatisfeitos, integrados e desintegrados. O cotidiano do trabalho, seja ele qual for, apresenta situações que podem representar para aqueles que o realizam significados positivos e negativos, concomitantemente. Uma pessoa pode gostar do seu trabalho e sofrer com ele ao mesmo tempo. Um trabalhador pode dizer estar satisfeito com suas tarefas, mas apresentar sintomas de adoecimento físico e/ou mental relacionados ao trabalho ${ }^{2}$.

Consideramos nossa análise a partir da compreensão do trabalho como atividade central na vida humana, ainda que, diante do desemprego estrutural e da nova configuração das formas de contratação e vínculos empregatícios, reconheçamos a necessidade de redimensionar os sentidos e os significados do trabalho na vida das pessoas (Antunes, 1995, 1999; Harvey, 2000). Isso quer dizer que, em cada época e lugar, as características do(s) trabalho(s) mudam e, além disso, que seu estudo requer a focalização por setores ou categorias das atividades laborais.

Neste artigo, fazemos um recorte de análise dos sentidos e da intensidade do trabalho e aspectos correlatos -, tomando como base trabalhadores de hotéis, especialmente gerentes, recepcionistas e camareiras ${ }^{3}$. Como os trabalhadores de hotel atribuem sentidos ao seu trabalho? Quais são as relações entre esses sentidos e as condições concretas de trabalho vividas no cotidiano de um hotel? Diante desse universo e dessas questões norteadoras da pesquisa que gerou esse artigo, organizamos nossas análises em três subitens: 1) os sentidos do trabalho; 2) a jornada e a intensidade do trabalho; e 3) os salários.

\footnotetext{
2 Reconhecemos que, algumas vezes, o trabalho pode ser desgastante e desinteressante, mas o bom salário pode trazer certa compensação pagando conforto, consumo, lazer e reposição da energia perdida no trabalho. No entanto, trata-se de um sentido extrínseco ao trabalho que ocorre numa lógica funcionalista-compensatória muitas vezes até interessante para os empregadores no interior do capitalismo. Não estamos tratando aqui desse tipo de compensação quando analisamos os sentidos do trabalho em relação às condições concretas dessas categorias de trabalhadores, mesmo porque eles estão justamente nos mostrando um sério comprometimento do equilíbrio entre tempo de trabalho e tempo de vida, necessário para que a compensação pudesse se realizar. Para uma análise crítica da relação compensatória entre trabalho e lazer, conferir Padilha (2000).

3 Hotéis são empreendimentos que fazem parte do chamado "setor de serviços". Dados evidenciam que Canadá, Estados Unidos e alguns países europeus possuem 75\% de seus empregos nesse setor (OECD, 2010; Kinman, 2009; Lewis \& Simpson, 2009). No Brasil, segundo dados do Ministério do Trabalho e Emprego, cerca de $72 \%$ dos empregos estão concentrados no setor de serviços (Brasil, 2008). Nas operações de serviços, uma parte das atividades é realizada na presença dos usuários ou clientes. Nesses casos, os trabalhadores estabelecem relações diretas com os clientes e encontram-se subordinados aos seus interesses, como os recepcionistas de hotéis. No entanto, existe um conjunto de atividades executadas na retaguarda, ou seja, sem interação direta com os clientes. Essas atividades costumam ser mais padronizadas e rotineiras, como é o caso das camareiras de hotéis.
} 


\section{Metodologia: os caminhos percorridos}

A pesquisa, de caráter eminentemente qualitativo, baseou-se no levantamento bibliográfico sobre os sentidos e a intensidade do trabalho. Compreendeu também a coleta de informações sobre o setor hoteleiro. Foram escolhidos dois hotéis na cidade de Ribeirão Preto (SP): um da categoria luxo, de gestão familiar, e um da categoria econômico, pertencente a uma grande rede de hotelaria internacional. Nos dois casos, algumas reuniões iniciais foram feitas com gerentes, para explicar as etapas da pesquisa e para colher informações sobre os hotéis. Nessa fase do trabalho foram entrevistados três gerentes: dois do hotel de luxo e um do hotel econômico. $\mathrm{Na}$ ocasião, foram acordadas as demais entrevistas em profundidade com gerentes, camareiras e recepcionistas, abordando aspectos sobre centralidade do trabalho, os sentidos do trabalho, jornada, salário, equilíbrio trabalho-vida privada e relações com o sindicato. A escolha dos indivíduos ocorreu em função da disponibilidade e aceitação em participar da pesquisa.

No hotel de segmento econômico, denominado aqui Hotel A, foram realizadas seis entrevistas: uma com o assistente de gerência, duas com recepcionistas, considerando-se um do gênero feminino e outro do masculino, e três entrevistas com camareiras, todas mulheres. No hotel de segmento luxo, denominado Hotel B, foram realizadas cinco entrevistas, sendo uma gerente de hospedagem, um recepcionista homem e três camareiras mulheres. Todas as entrevistas foram realizadas no próprio hotel e duraram cerca de uma hora e meia, foram áudiogravadas e depois transcritas para análise. Os resultados foram categorizados da seguinte forma, para todos os níveis de profissionais entrevistados: 1) os sentidos do trabalho, o que compreendeu os objetivos de vida e suas relações com o trabalho, a centralidade do trabalho; 2) jornada e intensidade do trabalho, o que compreendeu a duração do tempo de trabalho, a intensidade e as relações com a vida privada; 3 ) salários. O quadro 1 a seguir apresenta o perfil dos entrevistados.

\section{Quadro 1: Perfil dos entrevistados nos hotéis A e B}

\begin{tabular}{|l|l|l|l|l|}
\hline \multicolumn{2}{|l|}{ Entrevistados } & Gênero & Idade & Nível Educacional \\
\hline \multirow{4}{*}{ Hotel A } & Gerente & Masculino & 29 anos & Superior completo \\
\cline { 2 - 5 } & Recepcionista 1 & Feminino & 23 anos & Superior completo \\
\cline { 2 - 5 } & Recepcionista 2 & Masculino & 21 anos & Ensino médio completo \\
\cline { 2 - 5 } & Camareira 1 & Feminino & 38 anos & Ensino fundamental incompleto \\
\cline { 2 - 5 } & Camareira 2 & Feminino & 32 anos & Ensino fundamental incompleto \\
\cline { 2 - 5 } & Camareira 3 & Feminino & 39 anos & Ensino médio completo \\
\hline \multirow{5}{*}{ Hotel B } & Gerente & Feminino & 35 anos & Ensino superior completo \\
\cline { 2 - 5 } & Recepcionista & Masculino & 23 anos & Ensino superior completo \\
\cline { 2 - 5 } & Camareira 1 & Feminino & 38 anos & Ensino fundamental completo \\
\cline { 2 - 5 } & Camareira 2 & Feminino & 32 anos & Ensino fundamental completo \\
\cline { 2 - 4 } & Camareira 3 & Feminino & 28 anos & Ensino médio completo \\
\hline
\end{tabular}

Optamos pela entrevista em profundidade, por esta ser uma importante técnica de coleta de dados qualitativos. A entrevista é mais que um diálogo, é uma discussão orientada para um objetivo definido, que através da comunicação leva o entrevistado a expor sobre os temas específicos, gerando dessa forma informações para a pesquisa (Arnoldi \& Rosa, 2006).

Para a realização das entrevistas foi construído um roteiro. A utilização de entrevistas em profundidade limita as possibilidades de generalização dos resultados. No entanto, permite a 
verbalização de pensamentos, valores, sentimentos e pontos de vista sobre o tema, aprofundando o conhecimento sobre um determinado fenômeno e os significados a ele atribuídos (Kidder \& Judd, 1986).

A seguir apresentamos as análises das entrevistas, conforme as categorias estabelecidas anteriormente.

\section{Os sentidos do trabalho}

Existem vários estudos sobre os sentidos do trabalho, tais como Hackman e Oldhan (1975, 1976), Morin (2001), Oliveira et al. (2004), Piccinini e Tolfo (2007). Nesses estudos, são apresentados diversos aspectos para compreender os sentidos atribuídos ao trabalho.

Para Oliveira et al. (2004), por exemplo, um trabalho com sentido pode ser influenciado por quatro variáveis subjetivas: a) o significado do trabalho, entendido como a concepção do que é trabalho para o indivíduo; b) o valor - grau de importância, centralidade que o sujeito atribui ao trabalho; c) os valores éticos individuais; e d) o motivo, a razão, pelo qual trabalha. No entanto, segundo os autores, essas variáveis são altamente influenciadas pelo meio no qual o indivíduo está inserido, ou seja, por fatores culturais e sociais. Fox (citado por Morin \& Aubé, 2009, p. 118) identifica oito significações pessoais atribuídas ao trabalho, quais sejam: 1) o trabalho dá sentimento de pertença à sociedade e de que se pode ser útil; 2) permite criar vínculos de amizade; 3) permite obter status e respeito dos outros; 4) oferece possibilidade de definir sua identidade social; 5) permite organizar o tempo da vida cotidiana; 6) ajuda a superar problemas existentes na vida do ser humano; 7) permite que as pessoas se realizem ao se depararem com desafios; e, 8) permite transcender a existência humana.

Nesta pesquisa, utilizamos três componentes estabelecidos objetivamente por Morin e Aubé (2009): 1) a significação do trabalho para o indivíduo é a definição do trabalho, o conhecimento e a compreensão que o indivíduo tem dele, ou seja, é a representação do trabalho a partir da centralidade, da importância atribuída; 2) a orientação do indivíduo quanto ao trabalho é a função do trabalho, ou seja, a finalidade, a intenção associada ao trabalho, as razões pelas quais as pessoas trabalham e quais resultados pessoais são buscados na atividade laboral; 3) a coerência que o trabalho tem para o indivíduo é a relação do indivíduo com o trabalho, como ele equilibra sua vida com seu trabalho. De forma geral, podemos nos ater a como as pessoas concebem o trabalho e quais são os valores atribuídos a ele para compreendermos os seus sentidos ${ }^{4}$.

Procuramos problematizar esses três componentes visualizando o trabalho no hotel de forma a abarcar sua afirmação e sua negação, para usar expressão de Antunes (1999). Ou seja, em que pesem as múltiplas possibilidades que uma parcela dos trabalhadores tem de encontrar no trabalho todas as significações elencadas pelos autores citados, é preciso trazer para a análise as contradições e paradoxos inerentes aos processos e relações de trabalho. Dito de outra forma, o fato de o trabalho ser central na vida das pessoas não significa que as realidades de trabalho - com toda a sua diversidade - sejam imunes a angústias, sofrimentos, fadigas, acidentes ou adoecimentos. Na condição de atividade central da vida humana, o trabalho pode ter significados positivos e negativos aos trabalhadores.

4 Vale reconhecer que há uma grande variedade na abordagem do trabalho quando tomado pelas diferentes correntes epistemológicas e metodológicas da psicologia, da sociologia e da administração. A Psicologia Social do Trabalho, por exemplo, tem se destacado como uma corrente crítica no campo de estudos sobre trabalho, apesar de pouco ter publicado no Brasil especificamente sobre os sentidos atribuídos ao trabalho, tendo privilegiado estudos focados nos nexos causais entre trabalho e doença/saúde. Embora esta temática esteja sendo tratada com bastante pertinácia pelos autores nacionais da Psicologia Social do Trabalho, não caberia desenvolver aqui suas teorias, sob risco de fugir do escopo deste artigo. 
No desenvolvimento de nossa pesquisa no setor hoteleiro, percebemos essas contradições todo o tempo, quando confrontamos as condições de trabalho com os depoimentos dos trabalhadores. Num primeiro momento, foi possível identificar os objetivos de vida e os sentidos atribuídos ao trabalho por camareiras, recepcionistas e gerentes de hotéis.

A centralidade do trabalho aparece de forma marcante nas falas dos entrevistados. Tanto no caso das camareiras quanto para os recepcionistas e gerentes, os objetivos de vida remetem ao trabalho. Isso pode ser observado nas seguintes afirmações dos entrevistados, diante da indagação de quais seriam seus principais objetivos na vida:

Objetivos, eu penso assim, terminar os meus estudos e achar um serviço melhor do que eu já estou, né? E pode ser que eu cresça na empresa também, tudo depende do meu esforço (Camareira).

Meu principal objetivo é subir de cargo onde eu estou atualmente, né, e constituir família... (Recepcionista).

Viver com qualidade de vida, viver com uma carreira profissional bem-sucedida (Gerente).

[...] a gente precisa trabalhar, se não for aqui, vai ser em outro lugar. Então, normal, isso é uma coisa do dia a dia que todos nós temos que ter, né? Ninguém vive sem trabalho [...] (Camareira).

O trabalho aparece como único meio de atingir os objetivos de vida desejados, como pode ser visto na seguinte afirmação:

[...] eu quero mesmo ter minha família e aí, para ter minha família, eu preciso ter uma profissão muito boa (Recepcionista).

Para recepcionistas e camareiras, observamos principalmente os aspectos relativos à independência e sobrevivência, mesmo quando acompanhados de outro elemento que complete o sentido do trabalho, como, por exemplo, crescer dentro do hotel. Isso é possível observar nas seguintes declarações:

Daqui eu tiro o meu sustento, pra minha casa, pra tudo...

Ah, eu acho importante a gente ter um trabalho, ter seu próprio dinheiro, é uma qualidade de vida que eu não abro mão de trabalhar para ter.

Ganhar bastante para pagar a faculdade de medicina.

[...] paga todas as minhas contas, só.

Eu espero ganhar bastante conhecimento, além de crescer profissionalmente, virar gerente geral ou alguma coisa assim.

Crescer profissionalmente e [...] aprender bastante, porque eu gosto do ramo de hotelaria, então o que eu quero é crescer aqui dentro.

Já para os gerentes um tema recorrente foi o crescimento profissional e a identidade expressa pelo fato de a empresa onde trabalha ser reconhecida. O elemento satisfação pessoal também aparece sob a forma de adequação da atividade ou função desempenhada à formação profissional. Isso pode ser observado nos seguintes depoimentos:

Significa primeiro uma conquista, porque eu estudei turismo e hotelaria, e as pessoas que estudam turismo e hotelaria, elas reconhecem o mercado e a atividade como um todo [...] e essa empresa, ela é reconhecida mundialmente como pioneira e líder do mercado de administração de hotéis; então, é uma das empresas mais bem vistas, mais elogiadas no mercado hoteleiro como um todo.

Eu vejo muito pouca coisa negativa. Na verdade nós temos muitas tarefas; realmente, quem às vezes enxerga de fora acha até que a gente é de ferro, pela quantidade de coisas que a gente faz 
(...) (continuaria aqui) primeiro pela grandeza da empresa, segundo pela minha aprendizagem e pela possibilidade de crescimento profissional.

[...] hoje estou bastante satisfeito, assim, é bastante estresse, é bastante corrido, mas a gente aprende muito, a gente tem uma autonomia muito grande de trabalho e isso nos deixa bastante satisfeito.

Agora eu cheguei aonde en queria, que era ser gerente de um hotel, que eu estudei para isso.

Você não fica rico trabalhando em hotel, mas é muito gratificante.

Observamos, assim, diferenças entre as categorias de camareiras e recepcionistas e as do gerente, o que vem ao encontro das proposições de Oliveira et al. (2004), de que os sentidos do trabalho podem variar segundo a classe social e o meio no qual o trabalhador está inserido. Para camareiras e recepcionistas, a ideia de independência e sobrevivência aparece de forma contundente. A garantia de condições mínimas de sobrevivência dá sentido ao trabalho, mesmo que isso implique longas e intensas jornadas de trabalho, como veremos a seguir.

Para os gerentes, o crescimento profissional e a identidade são os elementos, mencionados pelos entrevistados, que dão sentido ao trabalho. Chama a atenção, nesse caso, que os entrevistados reconhecem e suportam o estresse a que são submetidos no trabalho em nome do status de trabalhar no que se formou e, principalmente, numa empresa reconhecida.

Nesse aspecto dos sentidos atribuídos ao trabalho, percebemos em quase a totalidade dos depoimentos que crescer profissionalmente e estudar mais para que isso ocorra está extremamente relacionado com os objetivos construídos por essas pessoas para suas vidas, corroborando a ideia do trabalho como atividade central. Para todos os entrevistados, trabalhar bem, de modo a satisfazer o cliente, mostra um lado positivo do trabalho e é sinal de eficiência, ou seja, a valorização do seu próprio trabalho está profundamente associada com a percepção que o outro, recebedor dos resultados de seu labor, demonstra ter.

Uma recepcionista menciona a satisfação do cliente quando foi perguntada sobre o que vê de positivo no seu trabalho:

A satisfação das pessoas, que elas estão sendo bem tratadas, que elas "tão" gostando, isso é muito positivo. Que nem, eu falei que eu trabalhei com criança, ver o sorriso de uma criança, entendeu, é bem gratificante. Atender as expectativas, você ver que a pessoa "tá" gostando do seu trabalho, que a pessoa "tá" satisfeita, vem um hóspede agradecer pela atenção, dar os parabéns, receber um elogio é um incentivo. Vê essa situação do hóspede já é bom já.

Uma camareira ressalta que a valorização do seu trabalho é feita pelo hóspede e não pelas chefias:

[...] Porque não é o daqui que vai vê o tipo de trabalho seu, já chegou hóspede mesmo e falou:

"Você é uma excelente pessoa; continue assim, que nunca vai te faltar serviço em lugar nenhum".

Trabalhar por necessidade financeira aparece como uma justificativa muito mais nas falas das camareiras, seguidas dos recepcionistas, que nas falas dos gerentes. Aparece ainda, de forma geral, nos depoimentos colhidos dos três níveis de profissionais, relatos que associam o trabalho ao estresse, à necessidade de estar disponível ao hotel, ao esforço contínuo, ao cansaço físico e mental, à sobrecarga e excesso de trabalho. Esses achados de pesquisa nos levaram a olhar mais de perto a relação entre os sentidos do trabalho e as condições de organização do tempo, da jornada, do ritmo e da intensidade impostos pelo trabalho em hotéis. 


\section{Jornada e intensidade do trabalho no setor hoteleiro}

Nossa pesquisa evidencia que trabalhadores de hotéis trabalham muito, considerando tanto a extensão da jornada quanto a intensidade do trabalho. Em hotéis, assim como em outros estabelecimentos no ramo da hospitalidade (clubes, shopping centers, restaurantes), há uma nítida demanda de dedicação ao trabalho em finais de semana e feriados, pois raramente fecham e costumam ficar mais movimentados em dias de descanso e lazer para outras pessoas.

Um recepcionista, ao ser perguntado sobre o que acha que o hotel espera dele, respondeu:

O máximo, o máximo do máximo do máximo! Você tem que estar pronto para quando eles precisarem.

Entendemos, a partir dos estudos de Dal Rosso $(2006,2008)$, que a jornada se expressa pela duração do tempo do trabalho, ou seja, "compreende a quantidade de tempo que o trabalho consome das vidas das pessoas" (Dal Rosso, 2006, p. 31). Dessa forma, a jornada de trabalho - que pode ser medida em horas ou dias, sendo a jornada semanal normalmente referência para a normatização que limita as jornadas máximas permitidas no País - guarda uma relação direta com a qualidade de vida e a saúde dos trabalhadores, pois estabelece não só o tempo dedicado ao trabalho como o tempo livre a ser usufruído.

A intensidade refere-se "ao consumo de energias pessoais e grupais no trabalho, expressa de outra maneira como sendo o esforço despendido pelos(as) trabalhadores(as) em seu labor cotidiano" (Dal Rosso, 2006, p. 33). Enquanto a jornada se refere à duração em tempo, a intensidade tem a ver com o investimento de energias, o que, em última instância, significa o desgaste das pessoas com o trabalho. A intensidade é mais que esforço físico, pois envolve as capacidades mentais, emocionais e saberes dos trabalhadores. "Quanto maior é a intensidade, mais trabalho é produzido no mesmo período de tempo considerado" (Dal Rosso, 2008, p. 21).

Tanto a extensão da jornada quanto a intensificação trazem elementos de exploração da força de trabalho aliados aos ganhos de produtividade. A intensificação no trabalho pode vir do aumento ou da diminuição da jornada de trabalho, mas sempre vem com o aumento da produtividade num primeiro plano, segundo Dal Rosso $(2006,2008)$. Esse autor afirma que a intensificação do trabalho é a face oculta do crescimento econômico: não são apenas mudanças técnicas que trazem ganhos de produtividade, mas também, e cada vez mais, a "majoração da intensidade do esforço daqueles que trabalham ou de grupos dos trabalhadores" (Dal Rosso, 2008, p. 27). Suas pesquisas nesse tema revelam que o setor de serviços - aquele que depende do chamado trabalho imaterial - é o que mais vem apresentando dados de intensificação, apesar de reconhecer a dificuldade na mensura da intensidade, visto que cada pessoa suporta diferentemente os desgastes físicos e mentais do trabalho.

Para Dal Rosso (2008), a intensidade do trabalho pode ser observada a partir dos seguintes fatores: 1) alongamento das jornadas por meio de horas extras pagas ou não-pagas; 2) elevação do ritmo e da velocidade; 3) acúmulo de atividades, ou seja, mais trabalho sobre os ombros dos mesmos indivíduos; 4) polivalência, versatilidade e flexibilidade, uma vez que os trabalhadores são chamados a atuar em diversas e diferentes frentes e a realizar mais trabalho no mesmo tempo; e 5) gestão por resultados, que pode ser entendida como uma forma mais subjetiva de intensificação. Todos esses fatores, de certa forma, levam ao que podemos denominar como "intensidade de si no tempo" (Aubert, 2003).

Cardoso $(2009$, p. 49) também afirma que novas formas de gestão nas organizações intensificam o trabalho quando há aumento da velocidade na execução dos gestos e uma redução na porosidade do trabalho - ou seja, nos tempos mortos, tempos de pausas e de 
descanso no meio da jornada. A intensificação do trabalho também pode ser compreendida, nesse contexto, como o trabalho em "fluxo tenso" (em francês, "flux tendu"), um método que visa gerar uma produção mais rápida com mínimo de custos e de tempos mortos, numa sociedade doente que cultua a urgência (Aubert, 2003). Esse imperativo de usar o tempo de trabalho no seu máximo, com o mínimo de paradas, aliado à chamada "flexibilidade" colocam os trabalhadores dos tempos atuais, no geral, em um quadro de polivalência e multifuncionalidade que exige mais trabalho - tanto em termos de horas quanto de intensidade.

Nesse cenário, a quantidade e a intensidade do trabalho não são definidas pelos trabalhadores, mas pelos empresários e gestores pautados pelas demandas flexíveis da produção. "Para o trabalhador, como consequência, o tempo de trabalho passa a ser diverso, diferente, desigual ao longo do dia, da semana, do mês, do ano ou da vida. Mas, sobretudo, a novidade é que seu tempo de trabalho torna-se cada vez mais imprevisível" (Cardoso, 2009, pp. 84-85, grifos no original).

No caso dos hotéis estudados, a jornada regulamentada é de 44 horas semanais, com direito a uma folga semanal, em qualquer dia da semana, e pelo menos uma folga em um domingo por mês para camareiras e recepcionistas. Para as camareiras e recepcionistas entrevistados, de forma geral, há uma sensação de que se trabalha muito, o que piora nos dias de folga ou férias de colegas ou quando o hotel está lotado.

Uma camareira afirma que até gosta do horário, mas que fica pior quando o hotel está cheio. Ela diz:

[...] porque o horário da gente é um horário bom, a gente entra às oito e sai às quatro e vinte; se for que o hotel tá tranquilo, a gente faz o serviço no horário que a gente dá. Só quando o horário tá $100 \%$ que a gente trabalha mais um pouco, mas é o adequado mesmo, das oito às quatro e vinte, tem dia que tá tranquilo, numa boa.

Quando alguém está de folga, há sobrecarga de trabalho:

A gente fica assim super carregado porque a gente faz o serviço da gente e ainda tem que fazer o da outra pessoa, mas acho que isso é no dia a dia, o que tem que ser feito, tem que dar conta, porque tá precisando, o hóspede também tá hospedado, vai precisar, e a gente carrega um pouco, mas faz parte do dia, né?

Quando perguntada se teria alguma sugestão para melhorar as condições e as relações do trabalho, uma das camareiras respondeu:

No nosso caso, como camareira, a gente precisaria de mais uma, tipo uma folguista para cobrir férias, porque quando uma sai de férias tá sempre sobrecarregando a gente de serviço, aí eu acho que...

Por que ela não continuou a sua frase? Estaria escondida nessa reticência sua opinião em relação ao fato de o hotel não planejar a contratação de folguistas ou sua sensação de ter de trabalhar mais para realizar as tarefas dos outros?

Os recepcionistas também relatam dificuldades na jornada quando há colegas ausentes. Uma recepcionista diz que se sente sobrecarregada e afirma:

Por falta de ter gente para trabalhar, falta de mão de obra, acaba sobrecarregando a gente em alguns setores. [...] semana passada mesmo fiquei doente e a gente tá passando por um problema de terem duas pessoas de férias, demissões e por conta disso sobrecarregou o meu horário; então, en tive que mudar a folga de uma pessoa para eu poder pegar o dia, para eu poder ficar em casa. 
disse:

Outro recepcionista, quando perguntado sobre o que ocorre quando falta no serviço,

Eu nunca tive problema, o pessoal que trabalha comigo trabalha direitinho, quando alguém falta fica bem corrido, ou você dobra, como eu falei, trabalhar 12 horas por dia, ou você tem que ligar pra alguém vir correndo.

Uma recepcionista contou que, quando alguém folga ou falta, o trabalho fica "mais sobrecarregado do que já é". E continua: "Eu trabalho 8 horas por dia, às vezes mais. Bom, é muito cansativo, como eu já disse, muito estresse mental".

Esses relatos parecem evidenciar que há um problema no planejamento do trabalho nos hotéis em relação às escalas de folgas, faltas e férias, pois ocorre sobrecarga para quem acumula o serviço da pessoa ausente. Por que os hotéis não ampliam seu quadro de pessoal e não contratam mais empregados para cobrirem as folgas e férias, nas diferentes funções? Por que essa sobrecarga de trabalho relatada não parece ser vista como um problema a ser resolvido pelo hotel? Os empregados podem ser chamados com urgência para cobrir uma falta, ou então são obrigados a dobrar um turno, fazer 12 horas seguidas ou mais, quando alguém falta. Eles devem estar $100 \%$ do tempo disponíveis para o hotel. Por quê?

A CLT (Consolidação das Leis do Trabalho), em seu artigo 59, diz: "A duração normal do trabalho poderá ser acrescida de horas suplementares, em número não excedente de 2 (duas), mediante acordo escrito entre empregador e empregado, ou mediante contrato coletivo de trabalho". Se a legislação trabalhista no Brasil proíbe que o trabalhador faça mais do que 2 horas extras por dia, como os hotéis conseguem fazer seus trabalhadores dobrarem turnos e prolongarem tanto a sua jornada? A Convenção Coletiva de Trabalho (firmada pelo sindicato dos empregados no comércio hoteleiro, restaurantes, bares, mercearias, panificadoras, pizzarias, churrascarias, lanchonetes, choperias, motéis, boates, flats, fast food e similares de Ribeirão Preto e região para o período entre 01/11/2008 e 31/10/2009) $)^{5}$ estabelece, na sua Cláusula 20aㅡ, sobre horas extras, que: "Fica estabelecido o adicional de hora extra de 50\% (cinquenta por cento), para as duas primeiras horas extras do dia e para as seguintes o percentual de 55\% (cinquenta e cinco por cento). Os adicionais em referência serão calculados com base no valor do salário-hora normal, excluídas as horas de trabalho compensadas".

Dessa forma, percebemos que o acordo coletivo dos trabalhadores desse setor ignora a normatização de horas extras expressa na CLT, permitindo o uso - e abuso - do tempo total do trabalhador em benefício da empresa. Tudo indica que o sindicato da categoria não tem incluído na sua agenda de negociações o problema da jornada de trabalho e das horas extras, o que se acentua pela indiferença dos funcionários em relação às questões sindicais. Todos os entrevistados revelaram desconhecer ou não se importar com o sindicato, apesar de pagarem uma vez ao ano, compulsoriamente, a contribuição sindical no valor correspondente a um dia de trabalho.

Sobre como a jornada semanal de trabalho influencia na vida familiar, uma camareira afirmou:

A gente tem uma folga por semana e um domingo só por mês, então é meio complicado almoçar com a família, fazer um aniversário, uma coisa assim é meio complicado; tudo tem que ser quando dá. Tem muitas coisas que eu deixei de ir porque ia trabalhar.

Outra camareira contou que já trabalhou e saiu três vezes do mesmo hotel. Quando foi perguntada sobre o motivo de ter saído, respondeu:

5 O documento da Convenção Coletiva foi enviado por e-mail pelo Sindicato, após solicitação das autoras. 
[...] é muito tempo que a gente fica aqui dentro. É sábado, domingo, feriado, Natal, Ano Novo, é todo dia. Então, é pouco tempo que eu fico com a minha família; aí, sei lá, eu estresso e saio.

Quando perguntada se, caso pudesse escolher, permaneceria nesse mesmo emprego, uma camareira respondeu que não e justificou:

Só pelo motivo de você ter que trabalhar direto sábado e domingo, se eu tivesse outra coisa que trabalhasse de segunda a sexta eu preferiria.

Um recepcionista, comentando sobre a relação entre o trabalho e a vida pessoal, diz:

É um pouco difícil, a carga horária aqui é meio complicada. Sempre "tá" trabalhando com seus colegas de trabalho. Você tem folga, os seus colegas "tão" trabalhando; então, não tem muito tempo pra você sair. Eu tô trabalhando aqui faz só cinco meses, eu tô conhecendo o pessoal, mas é que falta oportunidade, na verdade, de sair junto pela carga horária, pelo trabalho.

Ele ainda parece desculpar a organização do trabalho para jogar sobre si mesmo a responsabilidade por ser assim. Ele explica:

Eu acho assim, eu escolhi esse trabalho, então não posso reclamar, se ele atrapalha ou não é por minha causa, não por causa do trabalho, porque eu escolhi isso e eu sabia desde o começo que ia ser assim, num ia poder folgar fim de semana, não ia poder ficar com minha família, com minha namorada. Então, desde o começo eu sabia que era isso, agora se eu conhecer algum trabalho que só trabalhe de segunda-feira, é mais fácil e conveniente, mas como eu escolhi trabalhar dessa forma, eu acho que eu sabia disso, não é culpa do trabalho, a culpa é minha porque fui eu que escolhi.

Embora tenham direito a mais folgas nos finais de semana em relação aos outros funcionários dos hotéis, os gerentes entrevistados relatam excesso de trabalho e de responsabilidades, mas não demonstram desagrado por isso; ao contrário, parecem demonstrar orgulho por trabalharem demais. Uma gerente, por exemplo, relata que aos finais de semana não precisa trabalhar quando o hotel não está cheio, mas, mesmo assim, diz que passa no hotel para ver se está tudo certo.

Às minhas noites eu costumo ter tempo livre, porque eu trabalho geralmente até umas 19h, e final de semana, geralmente também é livre. Eu dou uma passada na empresa, mas não fico aqui o dia inteiro, não tenho que ficar. Só quando tem ocupação alta. Mas geralmente eu tenho meus finais de semana livres.

Eu não tenho muito horário de trabalho, mas normalmente eu entro às 9 h e saio às $18 \mathrm{~h}$. [...]. Mas meu horário é muito flexível, uma vez que eu sou um cargo de confiança e não bato cartão. Isso é uma coisa combinada. Então, se o hotel estiver lotado, eu estendo meu horário. No outro dia entro mais tarde, para dar meu horário de descanso, mas eu fico até mais tarde. De sábado e domingo eu venho ao hotel, quase todos os sábados e domingos, porque eu tenho que passar para ver como estão os departamentos.

Em outro momento da entrevista, ela reforça a sua informação de que trabalha nos finais de semana, mesmo sem ser sua obrigação:

Acabo trabalhando de final de semana, mas eu fico geralmente duas, três horas, não fico o dia inteiro. A não ser no meu plantão, que eu tenho um plantão de domingo no mês que é meu; então, eu fico aqui o dia inteiro. Mas fora isso eu venho aqui para ver se está tudo certo, para dar alguma obrigação para alguém fazer, e ver como está o atendimento dos hóspedes. 
Um gerente narra, com orgulho, sua jornada de 10 ou 11 horas diárias, em média:

Eu trabalho em média dez horas por dia. Isso é um pouco variável, dependendo das atividades que tenho no dia; então, por exemplo, amanhã nós temos uma reunião com dois diretores que vêm aqui para a unidade, eles já chegam às nove da manhã. Então, amanhã é um dia que eu venho mais cedo e eu acabo saindo tarde, da mesma forma, mas o normal é que, quando eu entro mais cedo, saio mais cedo. Se entro às nove, teoricamente eu sairia às sete, oito da noite, mas o normal seria das onze da manhã às dez da noite. Isso dá dez, onze horas de trabalho.

Quando perguntado se acha seu tempo de trabalho adequado para as tarefas que deve cumprir, ele responde:

Às vezes não, às vezes eu acho inadequado, pela quantidade de coisas; às vezes eu fico até me perguntando, me cobrando, será que eu tenho que ficar mais?

Vale a pena destacar e analisar esse pequeno trecho da entrevista com outra gerente, em que ela é indagada sobre como o trabalho interfere na sua vida pessoal.

Você acha que o seu trabalho prejudica de alguma forma a sua vida familiar?

Até agora não prejudicou.

Você acha que tem algum momento que pode prejudicar?

Eu acho que, talvez, quando eu me casar e tiver filhos. Talvez eu não vá ter a disponibilidade que eu tenho hoje, talvez a empresa não vá ter uma satisfação com a minha disponibilidade igual tem hoje, porque eu tenho uma disponibilidade total; a qualquer momento, precisou, eu estou aqui no hotel. Então, quando tiver filhos, eu não sei, porque não tive ainda, mas acredito que deve atrapalhar um pouco.

E você teria alguma sugestão para melhorar essa situação, se você tivesse filhos?

[...] Então, a sugestão que eu teria é ter uma babá em casa, morando 24 horas, porque aí eu teria a mesma disponibilidade, de vir fora do horário.

A disponibilidade total ao hotel, declarada pela gerente, demonstra sua intenção de dar o máximo de si e de seu tempo à empresa em que trabalha. E dar o máximo implica até sacrificar uma eventual experiência de maternidade. Ela sabe que o hotel aprova seu trabalho enquanto ela estiver disponível 24 horas por dia, todos os dias da semana. Se ela casar e tiver filho, a única maneira de manter-se nesse tipo de emprego com a mesma dedicação é "ter uma babá 24 horas por dia" para fazer o papel que seria dela como mãe.

O que leva uma pessoa a sacrificar o convívio com um filho pelo trabalho em tempo integral? O que existe na organização do trabalho em hotel para que um gerente se sinta "à vontade" para dizer o que ela disse? Ou haveria aí, implicitamente, um constrangimento, diante do hotel, de mostrar a mínima possibilidade de que sua dedicação integral ao trabalho possa ser ameaçada por algo da vida pessoal? Por que, mesmo quando estão de folga, os gerentes passam no hotel nos finais de semana?

Acreditamos em algumas possibilidades de respostas: a) isso ocorre pela própria natureza do trabalho da gerência, como representante "oficial" da empresa - é o que no senso comum se denomina "vestir a camisa", ou seja, o sentimento de ser proprietário do hotel; b) a própria organização do trabalho no hotel é centralizada na pessoa do gerente, de forma que a presença dele se faz fundamental para a realização das tarefas; e c) o perfil workaholic dos gerentes (Serva \& Ferreira, 2006).

A intensificação do trabalho para gerentes, recepcionistas e camareiras de hotéis pode ser percebida principalmente em duas situações típicas: quando o hotel está lotado e quando 
um funcionário está ausente por falta, folga ou férias. Isso reflete a ausência de planejamento e de interesse dos hotéis em criar escalas de folgas e estabelecer quantidade de funcionários adequada, de forma a não trazer sobrecarga de trabalho.

Nas categorias estudadas de gerentes, recepcionistas e camareiras, podemos afirmar que trabalhadores de hotéis trabalham jornadas alongadas, tanto em horas quanto em dias da semana, comprometendo sua vida pessoal e familiar. A vivência do tempo livre com parentes e amigos é difícil, devido à não coincidência dos dias de folga. A construção de família e de relacionamentos amorosos, para os mais jovens, parece ser um sonho prorrogável enquanto trabalhar no hotel. Os trabalhadores de hotéis devem colocar seu tempo à disposição da empresa, pois podem ser convocados ao trabalho a qualquer momento, mesmo em dias de folga ou quando já cumpriram seu expediente normal. Assim, o hotel faz uso das horas extraordinárias de seus funcionários sempre que precisar, levando o trabalhador a comprometer o equilíbrio entre trabalho e vida privada, perdendo qualidade de vida no trabalho e fora dele (Bohle et al., 2004; Martel \& Dupuis, 2006).

\section{Salários}

Passamos agora a discutir um aspecto central nas discussões sobre o trabalho: a questão salarial. Desde Taylor, várias correntes do pensamento administrativo, especialmente os behavioristas, buscam estabelecer uma relação entre salário e motivação para o trabalho. Alguns autores, como Bergamini (1997), advogam que se trata de um mito. No entanto, sua importância não pode ser menosprezada.

Segundo Oliveira et al. (2004), um trabalho faz sentido quando garante retorno financeiro e atende as necessidades básicas das pessoas, bem como quando traz independência financeira. Para Martel e Dupuis (2006), a percepção da remuneração como justa e adequada à carga de trabalho é positiva para o bem-estar do trabalhador e tem impactos importantes sobre a qualidade de vida no trabalho e a qualidade de vida das pessoas.

O quadro a seguir sintetiza e possibilita a visualização da correlação entre as informações de salários e o nível educacional por categoria dos entrevistados.

Quadro 2. Relação entre salários e níveis educacionais dos entrevistados dos hotéis A e B

\begin{tabular}{|l|l|l|l|l|}
\hline \multirow{2}{*}{$\begin{array}{l}\text { Categoria de trabalhadores } \\
\text { dos hotéis A e B }\end{array}$} & Salário* & Nível educacional \\
\cline { 2 - 5 } & Máximo & Mínimo & Máximo & Mínimo \\
\hline Camareiras & 2 salários mínimos & 1 salário mínimo & $\begin{array}{l}\text { Ensino médio } \\
\text { completo }\end{array}$ & $\begin{array}{l}\text { Ensino fundamental } \\
\text { incompleto }\end{array}$ \\
\hline Recepcionista & 4 salários mínimos & 3 salários mínimos & $\begin{array}{l}\text { Ensino superior } \\
\text { completo }\end{array}$ & $\begin{array}{l}\text { Ensino médio } \\
\text { completo }\end{array}$ \\
\hline Gerentes & 9 salários mínimos & 6 salários mínimos & Ensino superior completo \\
\hline
\end{tabular}

Tanto no Hotel A, quanto no Hotel B, as camareiras são a categoria de menor faixa salarial e também de menor nível educacional. Para 5 das 6 camareiras entrevistadas, os salários não são adequados à importância do trabalho delas para o hotel. Uma camareira diz: "[...] eu tenho muitos serviços e eu acho assim: que a camareira deveria ganhar um pouco mais, porque o hotel depende das camareiras; se não tem apartamento limpo, não tem hotel, não tem hospedagem[...]". Outra diz: "o salário eu acho pouco. Para ser sincera, pelo que a gente faz, eu acho pouco". Outra 
camareira mostrou certo conformismo com o salário, justificando sua posição em função do seu pouco nível de educação formal: "Eu não sou uma pessoa formada, você entendeu; eu só terminei o primeiro grau escolar, e pra mim [sic] ganhar um salário mais do que eu ganho aqui, eu tinha que ser uma pessoa formada".

Em ambos os hotéis estudados, os recepcionistas estão numa faixa salarial intermediária entre as camareiras e os gerentes, mas também não percebem seus salários como sendo compatíveis com o trabalho que executam, como ilustra a seguinte fala de um recepcionista: "Não [...], porque a gente trabalha muito para ganhar pouco".

Já os dois gerentes dos hotéis alegaram que seus salários são condizentes com o cargo que ocupam, como podemos observar nos seguintes trechos: "Sim, acho que é compatível", ou "[...] Hoje estou muito satisfeita com meu salário". Porém, em seguida, relativizaram, alegando que estão dentro do plano de carreira e pretendem subir na empresa, ou afirmando que o salário da categoria de gerentes de hotel deveria ser maior no município.

Independentemente da categoria, somente um entrevistado alegou conhecer a política salarial da região. Segundo o Sindicato de Hotéis, Restaurantes, Bares e Similares de Ribeirão Preto, em $1^{\mathrm{o}}$ de novembro de 2008, através de Convenção Coletiva de Trabalho, ficou estabelecido um piso salarial de $\mathrm{R} \$ 575,00$ (quinhentos e setenta e cinco reais), para os empregados do setor hoteleiro em Ribeirão Preto. Ou seja, cerca de 1,2 salário mínimo.

Assim, a categoria das camareiras está muito próxima do piso salarial, e é a que possui o menor nível de educação formal. Além disso, é a categoria que apresenta menor possibilidade de ascensão profissional.

De forma geral, independente da categoria, há insatisfação com os salários. Os hotéis tentam "complementar" os ganhos com benefícios, como cesta básica, alimentação, planos de saúde, esquemas de pontuação sobre a produtividade, aspectos que podem ter algum efeito positivo sobre o trabalhador e sobre o sentido que ele atribui ao trabalho. No entanto, é algo efêmero.

\section{Considerações finais}

Este artigo teve por objetivo compreender e analisar como os trabalhadores de hotel atribuem sentidos ao seu trabalho e quais são as relações entre esses sentidos e as condições concretas de trabalho vivenciadas no cotidiano desses hotéis. Para isso, foram realizadas, no total, 11 entrevistas em profundidade com gerentes, recepcionistas e camareiras em dois hotéis da cidade de Ribeirão Preto (SP). A análise dos depoimentos nos leva a concluir, a partir dos componentes de Morin e Aubé (2009), que o trabalho é central na vida dessas pessoas e é o meio pelo qual elas visam alcançar seus objetivos pessoais. Esses objetivos estão atrelados ao trabalho, mesmo que isso signifique jornadas laborais extensas, intensas e estressantes, com sacrifício da sua própria vida privada.

No que diz respeito ao componente da orientação do indivíduo quanto ao trabalho, podemos afirmar que as pessoas trabalham para atingir objetivos pessoais, como estudar, montar seu próprio negócio, capacitar-se para ascender na carreira, formar família etc. Entretanto, diante da grande dedicação e disponibilidade desses profissionais ao trabalho, percebe-se um salário insuficiente - principalmente para as categorias de recepcionistas e camareiras. No entanto, os hotéis estão seguindo o que determina a Convenção Coletiva do setor, em relação ao piso salarial, o que nos leva a pensar que há uma desarticulação entre as necessidades dos trabalhadores e a agenda do sindicato que os representa. 
Um aspecto importante de ser ressaltado é o fato de que faz parte do processo organizativo dos hotéis estudados a política de restrição do quadro de mão de obra, justificando, em grande parte, a extensão e a intensidade do trabalho para todas as categorias profissionais, visto que a sobrecarga, física e mental, de trabalho apareceu como uma queixa constante nos depoimentos. Podemos afirmar que esses resultados corroboram um padrão de gestão que vem sendo difundido nas últimas décadas, de eficiência, flexibilização, polivalência, os quais requerem dos trabalhadores maiores esforços físicos e mentais, além do enxugamento gradativo da força de trabalho (Cardoso, 2009; Dal Rosso, 2008; Harvey, 2000; Heloani, 2003; Hirata \& Zarifian, 1991; Lacaz, 2000).

No que tange à coerência que o trabalho tem para o indivíduo, ou como ele equilibra sua vida com o trabalho, os entrevistados relatam a necessidade de estarem disponíveis quase integralmente às demandas da empresa, mesmo depois do cumprimento da jornada normal de trabalho, ou ainda para suprir faltas e folgas de colegas. A causa desse desequilíbrio entre vida profissional e a pessoal não se encontra apenas numa esfera individual, visto que há relação direta com a dimensão organizacional. Isso sugere um projeto de trabalho pouco atento aos tempos e tarefas necessários ao desenvolvimento das atividades, o que também reforça o modelo atual de organização do trabalho e da produção, qual seja, o de buscar a máxima eficiência com base no empenho individual dos trabalhadores. Os níveis atuais de desemprego no país, as ameaças de demissão e a insegurança são sentimentos que podem estar presentes nos trabalhadores assalariados, e configuram-se em aliados das empresas, conforme sugerem Araújo (2008) e Castelhano (2005).

Além disso, o tempo do trabalhador se torna o tempo disponível para a empresa, que não leva em consideração a necessidade de haver tempos independentes para dedicação ao lazer, formação, cultura, família, atividades sociais, ou seja, a vida pessoal coincide com a vida da empresa (Hirata \& Zarifian, 1991; Martel \& Dupuis, 2006; Padilha, 2000; Tremblay, 2003). Como bem ilustrou a voz de uma entrevistada, "a gente fica muito tempo aqui dentro".

Esses achados da pesquisa nos remetem a questões para futuros estudos: estariam outros trabalhadores de hotéis no Brasil submetidos à mesma lógica organizacional e condições de trabalho? Qual deveria ser o papel dos sindicatos no enfrentamento coletivo dos problemas relacionados à extensão da jornada, intensidade no trabalho e baixos salários? Quanto das condições reais do trabalho descritas neste artigo remete a um quadro de precarização do trabalho? A realidade do trabalho em hotéis no Brasil oferece, sem dúvida, material fértil para os campos da psicologia social, da sociologia do trabalho e dos estudos críticos em administração.

\section{Referências}

Antunes, R. (1995). Adeus ao trabalho? Ensaio sobre as metamorfoses e a centralidade do mundo do trabalho. São Paulo: Cortez.

Antunes, R. (1999). Os sentidos do trabalho: ensaio sobre a afirmação e a negação do trabalho. São Paulo: Boitempo.

Araujo, J. N. G. (2008). Entre servidão e sedução do trabalhador: uma secular insistência do capital. In A. M. Mendes (Org.), Trabalho e saúde: o sujeito entre emancipação e servidão (pp. 54-68). Curitiba: Juruá.

Arnoldi, M. A. G. C. \& Rosa, M. V. F. P. C. (2006). A entrevista na pesquisa qualitativa: mecanismos para validação de resultados. Belo Horizonte: Autêntica.

Aubert, N. (2003). Le culte de l'urgence: la société malade du temps. Paris: Flammarion.

Brasil, Ministério do Trabalho e Emprego (2008). Relação Anual de Informações Sociais (RAIS): principais resultados. 
Bergamini, C. W. (1997). Motivação: mitos, crenças e mal-entendidos. In C. W. Bergamini \& R. Coda (Orgs.), Psicodinâmica da vida organizacional: motivação e liderança (pp. 69-93). São Paulo: Atlas.

Bohle, P., Quinlan, M., Kennedy, D. \& Williamson, A. (2004). Working hours, work-life conflict and health in precarious and "permanent" employment, Revista de Saúde Pública, 38 (suplemento), 19-25.

Cardoso, A. C. M. (2009). Tempos de trabalho, tempos de não trabalho: disputas em torno da jornada do trabalhador. São Paulo: Annablume/Fapesp.

Castelhano, L. M. (2005). O medo do desemprego e a(s) nova(s) organizações de trabalho. Psicologia $\mathcal{G}$ Sociedade, 17 (1), 17-28.

Dal Rosso, S. (2006). Jornada de trabalho: duração e intensidade. Ciência $\mathfrak{G}$ Cultura, 58 (4), 31-34.

Dal Rosso, S. (2008). Mais trabalho! A intensificação do labor na sociedade contemporânea. São Paulo: Boitempo.

Hackman, J. R. \& Oldham, G. R. (1976). Motivation through the design of work: test of a theory. Organizational Behavior and Human Performance, 16, 250-279.

Hackman, J. R. \& Oldham, G. R. (1975). Development of the job diagnostic survey. Journal of Applied Psychology, 60 (2), 159-170.

Harvey, D. (2000). Condição pós-moderna: uma pesquisa sobre as origens da mudança cultural (9a ed.). São Paulo: Loyola.

Heloani, R. (2003). Gestão e organização no capitalismo globalizado: história da manipulação psicológica no mundo do trabalho. São Paulo: Atlas.

Hirata, H. \& Zarifian, P. (1991). Força e fragilidade do modelo japonês, Estudos Avançados, 5 (12), 173-185.

Kidder, L. H. \& Judd, C. M. (1996). Research methods in social relations (5 ${ }^{\mathbf{a}}$ ed.). New York: Holt, Rinehart and Winston, CBS College Publishing.

Kinman, G. (2009). Emotional labour and strain in "front-line" service employees: does mode of delivery matter? Journal of Managerial Psychology, 24 (2), 118-135.

Lacaz, F. A. C. (2000). Qualidade de vida no trabalho e saúde/doença. Ciência e Saúde Coletiva, 5 (1), 151-161.

Lewis, P. \& Simpson, R. (2009). Centring and engendring emotions in service work. International Journal of Work, Organisation and Emotion, 3 (1), 56-64.

Martel, J. P. \& Dupuis, G. E. (2006). Quality of work life: theoretical and methodological problems, and presentation of a new model and measuring instrument. Social Indicators Research, 77 (2), 333-368.

Mintzberg, H. (2007). Produtividade que mata. GVExecutivo, 6 (6), 17-23.

Morin, E. (2001). Os sentidos do trabalho. Revista de Administração de Empresa, 41 (3), 8-19.

Morin, E. \& Aubé, C. (2009). Psicologia e gestão. São Paulo: Atlas.

MOW, International Research Team. (1987). The meaning of working. New York: Academic Press.

OECD. (2010). Entrepreneurship, industry and services statistics: what exactly are services? Paris: OECD.

Oliveira, S. R., Piccinini, V. C., Fontora, D. S. \& Schweig, C. (2004). Buscando o sentido do trabalho. In Anais do XXVIII Encontro da Associação Nacional do Pós-Graduação e Pesquisa em Administração. Porto Alegre, ANPAD.

Padilha, V. (2000). Tempo livre e capitalismo: um par imperfeito. Campinas: Alínea.

Piccinini, V. \& Tolfo, S. R. (2007). Sentidos e significados do trabalho: explorando conceitos, variáveis e estudos empíricos brasileiros. Psicologia $\mathcal{F}$ Sociedade, 19 (número especial), 38-46.

Serva, M. \& Ferreira, J. L. O. (2006). O fenômeno workaholic na gestão de empresas. RAP, 40 (2), 179-200.

Tremblay, D. G. (2003). Articulation emploi-famille: les usages du temps chez les pères et les mères. Revue Nouvelles Pratiques Sociales, 16 (1), 76-93.

\section{Endereço para correspondência}

valpadilha@usp.br,mgrande@usp.br

Recebido em: 10/02/2010

Revisado em: 28/07/2010

Aprovado em: 14/09/2010 